\title{
Critical gas velocity prediction for vortex drainage gas wells
}

\author{
Zhao Zhang ${ }^{1,2}$, Ruiquan Liao ${ }^{1,2 *}$, Peng Fu³ ${ }^{3}$ Yubin $\mathrm{Su}^{3}$, Wei Luo ${ }^{1,2}$, Dingxue Zhang ${ }^{1,2}$ \\ ${ }^{1}$ Petroleum Engineering College, Yangtze University, Wuhan 430100, China \\ ${ }^{2}$ Laboratory of Multiphase Pipe Flow, Gas Lift Innovation Center, CNPC, Wuhan 430100, China \\ ${ }^{3}$ Research Institute of Oil and Gas Technology, PetroChina Changqing Oilfield Branch Company, Xi'an 710021, China
}

Corresponding Author Email: liaoruiquan@163.com

https://doi.org/10.18280/ijht.360439

Received: 8 March 2018

Accepted: 6 July 2018

\section{Keywords:}

gas well, vortex tool, drainage gas recovery, critical gas velocity, swirling flow, friction factor, prediction model, reduction amplitude

\begin{abstract}
This paper attempts to disclose the law of critical gas velocity in the swirling flow field induced by the vortex tools. For this purpose, a critical gas velocity calculation model for vortex drainage gas wells was established based on the axial force balance between the liquid film and the gas core in swirling flow, and modified with the experimental data in previous studies. Then, the effects of helix angle and hub diameter of vortex tool on the reduction amplitude of critical gas velocity were analyzed by comparing the modified model with Turner model. Through experimental verification, it is learned that our new model can predict the critical gas velocity under different production conditions with different vortex tools. The reduction amplitude of critical gas velocity increased with the helix angle and decreased with the growth in hub diameter. The reduction amplitude ranged from $55.03 \%$ to $59.35 \%$ as the helix angle varied from $15^{\circ}$ to $75^{\circ}$ and the hub diameter varied from $34 \mathrm{~mm}$ to $50 \mathrm{~mm}$. The helix angle has a greater impact than the hub diameter on the reduction amplitude. The research findings shed new light on the design and application of the vortex tools.
\end{abstract}

\section{INTRODUCTION}

In 2011, the China National Petroleum Corporation (CNPC) introduced a new drainage gas recovery method called the deliquification by downhole vortex tool. By this method, the vortex tool is installed at a proper depth of the tube to transform the liquid-gas axial flow to a swirling flow with strong carrying capacity (Figure 1), thereby reducing critical gas flow rate and tubing pressure loss. Thus, the liquid loaded at the bottom hole can be removed and production efficiency of the gas well can be enhanced [1,2]. Compared with traditional methods, the new recovery method is cheap and easy to implement, because the vortex tool has no moving parts and needs no additional energy source.

At present, the new method is being tested in China's oil and gas fields, such as Xushen gas field, Sulige gas field, Sichuan gas field, Jilin oil field, Xinjiang oil field and YakelaDalaoba gas condensate field [3-5]. The field tests indicate that the gas and liquid production rate has been increased to different extents and the production conditions have been significantly improved in most test wells after the installation of the vortex tool. However, these effects are not obvious in Su 36-4-3 and a few other wells [3], probably due to the improper timing of tool application. To determine the right timing, the easiest way is to predict the liquid loading conditions of gas wells by the critical gas velocity. Unfortunately, there is little report on the critical gas velocity under swirling flow, which severely limits the promotion of vortex tools.

The critical gas velocity, the key evaluation basis for the liquid-unloading capabilities of gas wells [2], should be investigated thoroughly under swirling flow before recognizing the adaptability of the method of vortex drainage gas recovery. Nevertheless, the existing prediction models of critical gas velocity are mostly based on the axial flow, such as the typical liquid droplet models and liquid film models. The first critical gas velocity model was created by [6] in 1969, considering the force balance of the largest droplet dispersed in the gas flow. Since then, the model has been improved repeatedly by scholars at home and abroad. For instance, [7] and [8] modified the Turner model by treating the dispersed droplets as ellipsoids and globe caps like liquid drops, respectively. [9] introduced the Fiedler shape function into the Turner model to fit wells with different inclination angles. The effects of droplet deformation on critical Weber number and drag coefficient were taken into account in the prediction models designed by [10] and [11]. The liquid film models are generally more complex than liquid droplet models. [12] proposed a critical gas velocity correlation after analysing the force balance of the liquid film and gas core at the reversal of the liquid film. [13] modified the Richter correlation to fit the deviated gas wells, considering the effect of well deviation angle. [14] developed an analytical model to predict liquidloading onset based on the liquid film reversal criterion.

Compared with the mature research of critical gas velocity in axial flow, the study on critical gas velocity in swirling flow is still in its infancy. In 2003, [2] experimentally investigated the performance of the vortex tool, revealing that the tool can reduce the tubing pressure loss by up to $17 \%$ and lower the critical gas velocity of the gas well by up to $30 \%$. [15] suggested that the vortex tool can cut down the critical gas velocity by $20 \%$, an evidence of the tool's effectiveness in improving the liquid carrying capacity of the gas well. Based on the force balance of the largest liquid droplet in the swirling flow, [16] established a critical velocity calculation model and applied it to predict the critical gas velocity; the results show 
that the critical gas velocity first decreased and then increased with the growth in the helix angle of the vortex tool, but the amplitude of variation was small. In fact, the gas-liquid twophase fluid tends to form the annular flow due to the centrifugal force in the swirling field. Therefore, it is more rational to predict the critical gas velocity for gas wells with vortex tools using the liquid film model.

This paper attempts to build a prediction model of the critical gas velocity for vortex drainage gas wells, and disclose the effects of helix angle and hub diameter of vortex tool on the critical gas velocity. For these purposes, a critical gas velocity prediction model in the swirling flow field, which is induced by the vortex tools, was developed based on the axial force balance between the liquid film and the gas core; then, the proposed model was modified against the experimental results in existing studies, and verified through field tests; finally, the authors discussed the reduction of the critical gas velocity for vortex tools. The research findings help to promote the design and application of vortex tools.

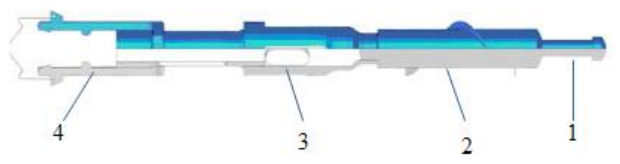

Figure 1a. Structure of the vortex tool

1-Fishing head; 2-Corkscrew deflector; 3-Draft tube; 4Setting device

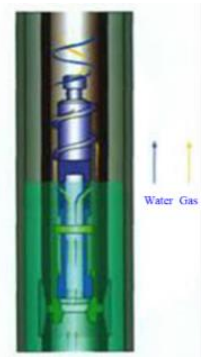

Figure 1b. Schematic diagram of the vortex tool

\section{PREDICTION MODEL FOR CRITICAL GAS VELOCITY IN SWIRLING FLOW}

\subsection{Model establishment}

After the downhole fluid flows through the vortex tool, the heavier liquid will gather towards the pipe wall under the centrifugal force, forming a liquid film, while the lighter gas will move towards the centre, creating a gas core. In this way, the gas-liquid two-phase flow is transformed into a swirling annular flow. For simplicity, the gas-liquid two-phase swirling annular flow is decomposed into an axial annular flow and a tangential circular flow. Inspired by Richter's analysis on vertical annular flow [12], a prediction model for the critical gas velocity in swirling flow was established based on the axial force balance of annular flow.

Assuming that the liquid film on the pipe wall is small and homogenous in thickness $(\delta / D<<1)$ (Figure 2), the force balance on the liquid phase and gas phase at the liquid film reversal can be expressed as:

$$
\begin{aligned}
& \tau_{w} \frac{S_{w}}{A_{f}}+\tau_{i} \frac{S_{i}}{A_{f}}+\left(\frac{d p}{d z}\right)_{f}-\rho_{l} g=0 \\
& -\tau_{i} \frac{S_{i}}{A_{c}}+\left(\frac{d p}{d z}\right)_{c}-\rho_{g} g=0
\end{aligned}
$$

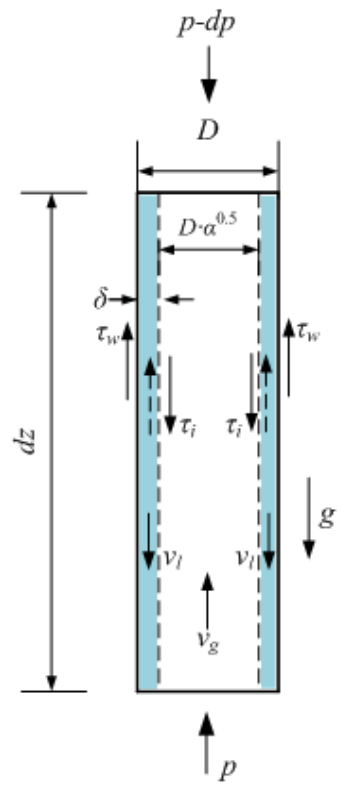

Figure 2. Force balance in the axial annular flow

Let $\varepsilon$ be the gas void fraction. Then, the perimeter and crosssectional area of liquid film and gas core can be expressed as:

$S_{w}=\pi D$

$A_{f}=\frac{\pi D^{2}}{4}(1-\varepsilon)$

$S_{i}=\pi \varepsilon^{0.5} D$

$A_{c}=\frac{\pi D^{2}}{4} \varepsilon$

When the liquid film is in balance with the air core, the following new correlation can be obtained from Eq. (1) to Eq. (6) by eliminating the pressure gradient:

$\frac{4 \tau_{w}}{D}+\frac{4 \tau_{i}}{D \sqrt{\varepsilon}}=\left(\rho_{l}-\rho_{g}\right) g(1-\varepsilon)$

According to Wallis' annular theory [17], the axial shear force between the liquid film and the pipe wall can be written as:

$\tau_{w}=\frac{1}{2} f_{s w} \rho_{l} v_{l}^{2}=\frac{1}{2} f_{s w} \rho_{l} \frac{v_{s l}^{2}}{(1-\varepsilon)^{2}}$

Similarly, the axial shear force between the liquid film and the gas core can be expressed as: 
$\tau_{i}=\frac{1}{2} f_{s i} \rho_{g}\left(v_{g}+v_{l}\right)^{2}$

where $f_{s w}$ and $f_{s i}$ are the wall friction factor and interfacial friction factor in the swirling field, respectively. Since $v_{l}<<v_{g}$ at the liquid film reversal, Eq. (9) can be simplified as:

$\tau_{i}=\frac{1}{2} f_{s i} \rho_{g} v_{g}^{2}=\frac{1}{2} f_{s i} \rho_{g} \frac{v_{s g}^{2}}{\varepsilon^{2}}$

Then, the relationship between the wall friction factor and interfacial friction factor can be described as:

$f_{s i}=f_{s w}\left(1+300 \frac{\delta}{D}\right)$

From the geometric meaning of the gas void fraction, the liquid void fraction can be evaluated as:

$1-\varepsilon=\frac{A_{F}}{A}=\frac{4 \delta}{D}\left(1-\frac{\delta}{D}\right) \approx \frac{4 \delta}{D}$

The liquid film reflows when the liquid cannot be carried upwards by the interfacial shear stress between the gas core and the liquid film, that is, $\tau_{i}<<\tau_{w}$. In this case, the following correlation can be obtained by combining Eqs. (3), (4) and (9):

$\frac{\delta}{D}=\left(\frac{f_{s w}}{32}\right)^{\frac{1}{3}} v_{l}^{* \frac{2}{3}}$

where $v_{l} *$ is the dimensionless liquid velocity,

$v_{l}^{*}=\frac{v_{s l} \rho_{l}^{0.5}}{\left[g D\left(\rho_{l}-\rho_{g}\right)\right]^{0.5}}$

Substituting Eq. (8) Eq. (14) into Eq. (7), the final expression can be obtained through dimensionless treatment:

$\frac{f_{s w}}{4} N_{B}^{3} v_{g}^{* 6} v_{l}^{* 2}+f_{s w} N_{B} v_{g}^{* 4}+150 f_{s w} v_{g}^{* 2}=1$

where $v_{g}{ }^{*}$ is the dimensionless gas velocity; $N_{B}$ is the Bond number.

$$
\begin{aligned}
& v_{g}^{*}=\frac{v_{s g} \rho_{g}{ }^{0.5}}{\left[g D\left(\rho_{l}-\rho_{g}\right)\right]^{0.5}} \\
& N_{B}=D^{2} \frac{g\left(\rho_{l}-\rho_{g}\right)}{\sigma}
\end{aligned}
$$

In the critical liquid-carrying state, the dimensionless liquid film velocity equals zero. The dimensionless gas velocity can be obtained from Eq. (15), $v_{g}^{*}=\frac{5 \sqrt{3}}{N_{B}^{0.5}}\left[\left(1+\frac{N_{B}}{75^{2} f_{s w}}\right)^{0.5}-1\right]^{0.5}$

According to Eq. (16) and Eq. (18), the critical gas velocity in swirling flow can be obtained as:

$v_{c r s}=\frac{5 \sqrt{3}}{N_{B}^{0.25}}\left[\left(1+\frac{N_{B}}{75^{2} f_{s w}}\right)^{0.5}-1\right]^{0.5}\left[\frac{g \sigma\left(\rho_{l}-\rho_{g}\right)}{\rho_{g}^{2}}\right]^{0.25}$

For simplicity, the $K u$ number is introduced below:

$K u=\frac{5 \sqrt{3}}{N_{B}^{0.25}}\left[\left(1+\frac{N_{B}}{75^{2} f_{s w}}\right)^{0.5}-1\right]^{0.5}$

Then, Eq. (19) can be transformed into:

$v_{c r s}=K u\left[\frac{g \sigma\left(\rho_{l}-\rho_{g}\right)}{\rho_{g}^{2}}\right]^{0.25}$

Therefore, the friction factor between the liquid film and the pipe wall in the swirling flow field is the key for the model to calculate the critical gas velocity of the vortex drainage gas well.

\subsection{Friction factor of swirling flow}

So far, there is no report on the friction factor of swirling flow induced by the vortex tool. The commonly used correlations of swirling friction factor are mainly developed from twisted tape, including Gambill correlation [18] and Lopina-Bergles correlation [19]. Gambill held that the twisted tape widens the frictional surface area of the fluid, such that the friction coefficient of the swirl flow becomes greater than that of the straight pipe axial flow, and established the following correlation:

$\frac{f_{s}}{f}=\frac{\left(4 y^{2}+\pi^{2}\right)^{3 / 2}}{8 y^{3}}$

where $f_{s}$ and $f$ are the friction factors in the pipe with and without twisted-tape, respectively; $y$ is the twist ratio, that is, the ratio between the tape turn length of $180^{\circ}$ along its axis and the tube diameter.

$y=\frac{L_{p}}{2 D}$

Lopina and Bergles also experimentally studied the friction factor inside tubes with twisted tape. They found that Gambill correlation is not suitable for the smooth tube systems, and provided the following smooth tube correlation:

$\frac{f_{s}}{f}=2.75 y^{-0.406}$ 
Obviously, the swirling friction factor induced by the twisted tape hinges on the axial friction factor and the twist ratio. Wallis [17] found that the axial friction factor was approximately 0.008 at the critical point. Thus, the value of $f$ is set to 0.008 in our research. The twist ratio of the vortex tool is related to its structural parameters. Here, the angle of the guide vane with respect to axial direction is defined as the helix angle $\varphi$. Then, the relationship between the helix angle, pitch, and pitch diameter of the guide vane can be expressed as:

$\tan \varphi=\frac{L_{p}}{\pi d_{p}}$

The pitch diameter can be written as:

$d_{p}=\frac{1}{2}\left(D+d_{v}\right)$

Substituting Eq. (25) and Eq. (26) into Eq. (23), the twist ratio of vortex tool can be obtained as:

$y_{v}=\frac{\pi\left(D+d_{v}\right)}{4 D \tan \varphi}$

The prediction method for the critical gas velocity in swirling flow induced by the vortex tool can be finalized by combining Eq. (20), (21), (22) and (24).

\section{MODEL \\ EVALUATION \\ AND \\ RESULTS \\ DISCUSSION}

\subsection{Model evaluation}

The model evaluation was carried out with reference to the experiment of Chen et al. [15, 20]. Specifically, the upward air-water two-phase flow was investigated in a vertical tube inserted a vortex tool at the pressure from 0.01 to $0.055 \mathrm{MPa}$. The inner diameter of the test pipe was $30 \mathrm{~mm}$. Three vortex tools with different helix angles $\left(30^{\circ}, 45^{\circ}\right.$, and $\left.50^{\circ}\right)$ were adopted to test the effect of helix angle on the critical gas velocity. These tools had the same hub diameter $(20 \mathrm{~mm})$ and maximum outer diameter $(30 \mathrm{~mm})$. In the experiment, the critical gas flow rate was defined as the gas flow rate when the water phase began to flow back. The experimental setup is shown as Figure 3.

The critical gas velocities under different experimental conditions were calculated by Zhou's model, new model I and new model II, respectively. New model I and new model II differ in the friction factor correlation. In the former model, the friction factor was calculated by Eq. (22); in the latter model, the friction factor was calculated by Eq. (24). The critical gas velocities predicted by different models are contrasted with the measured data in Figures $4 \sim 6$ below.

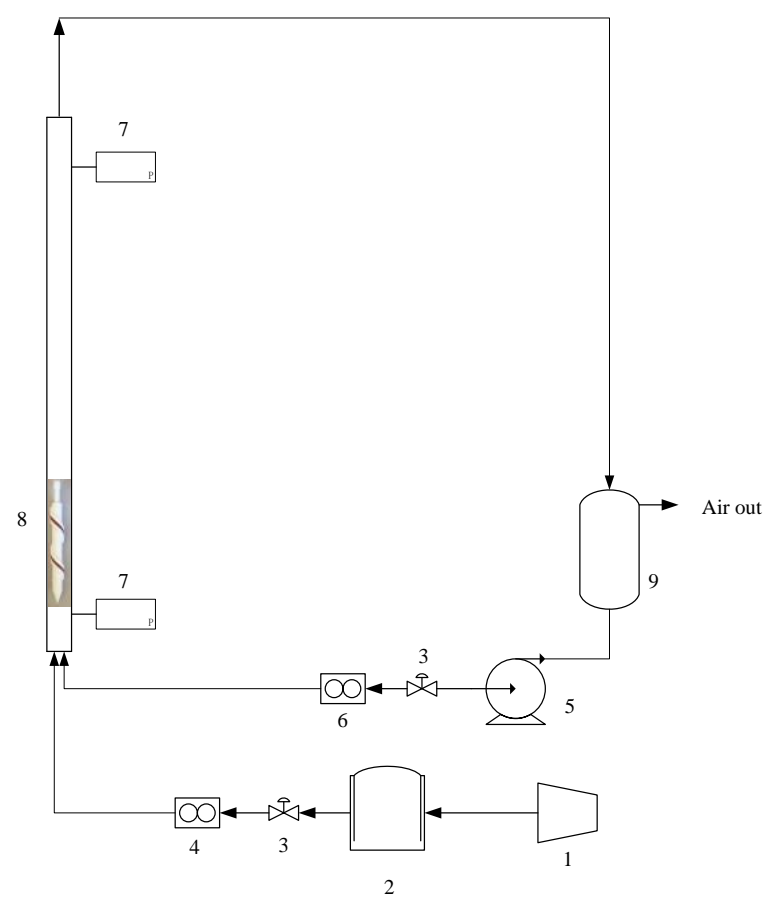

Figure 3. Flow chart of experimental facilities

1- Air compressor; 2- Air tank; 3- Manual valve; 4- Gas flowmeter; 5Centrifugal pump; 6- Liquid flowmeter; 7- Pressure transducer; 8-Vortex tool; 9-Seperating tank.

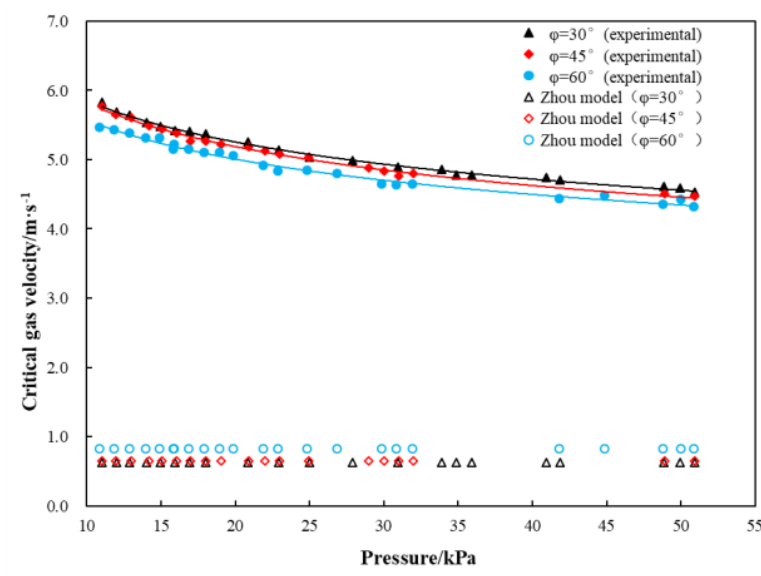

Figure 4. Comparison of critical gas velocity predicted by Zhou's model with measured data

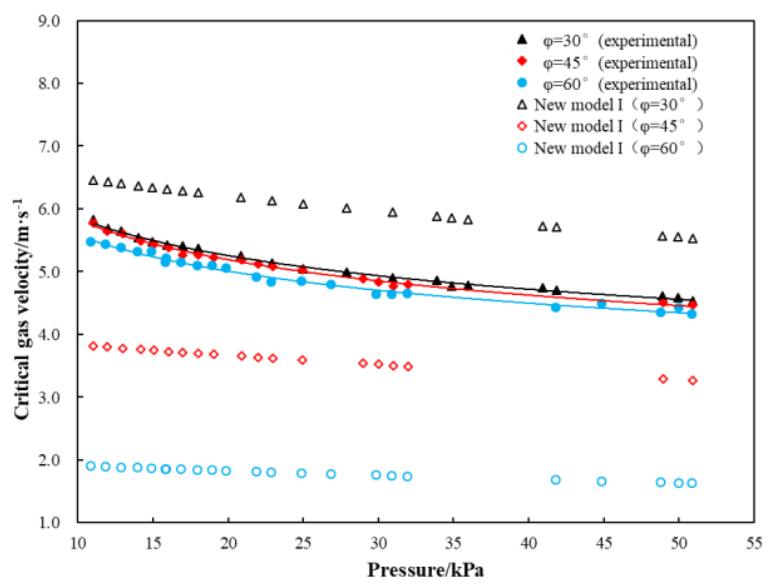

Figure 5. Comparison of critical gas velocity predicted by new model I with measured data 


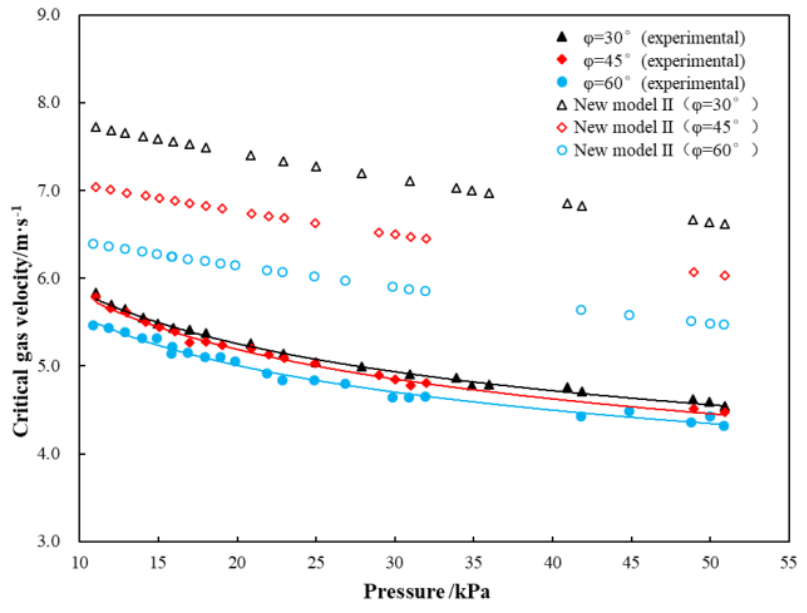

Figure 6. Comparison of critical gas velocity predicted by new model II with measured data

As shown in Figure 4, the critical gas velocity predicted by Zhou's model fell between 0 and $1 \mathrm{~m} / \mathrm{s}$, which is considerably different in magnitude from the measured data and slightly affected by the helix angle. This means Zhou's model is not suitable for computing the critical gas velocity in this experiment. It can be seen from Figure 5 that the critical gas velocity predicted by new model I is sensitive to the helix angle of the vortex tool. The predicted value was greater than the measured value at the helix angle of $30^{\circ}$, but smaller than the latter at the helix angles of $45^{\circ}$ and $60^{\circ}$. According to Figure 6 , the critical gas velocity predicted by new model II was higher than the measured data, and the computing error decreased with the growth in the helix angle.

Table 1 displays the absolute mean errors of new models at different helix angles. The absolute mean errors of the two new models were $38.30 \%$ and $31.21 \%$, respectively, indicating that the new models have relatively high computing errors compared with the measured data.

Table 1. Absolute mean errors of new models at different helix angles

\begin{tabular}{ccccc}
\hline \multirow{2}{*}{ Model } & \multicolumn{4}{c}{ Absolute mean error (\%) } \\
\cline { 2 - 5 } & $\varphi=30^{\circ}$ & $\varphi=45^{\circ}$ & $\varphi=60^{\circ}$ & Total \\
\hline New model I & 18.51 & 29.53 & 63.61 & 38.30 \\
New model II & 41.65 & 30.01 & 22.68 & 31.21 \\
\hline
\end{tabular}

\subsection{Modification of friction factor correlation}

The high absolute mean errors of the new models are attributable to the calculation methods of the friction factor in the swirling flow. In fact, the friction factor correlation developed based on twisted tape should not be directly used for the case of vortex tool. There are structural differences between the vortex tool and the twisted tape. For instance, the former has a hub part that is not included in the twisted tape. To solve the problem, Eq. (22) and Eq. (24) can be modified as:

$$
\frac{f_{s}}{f}=5.297\left(1+\frac{\pi^{2}}{4 y^{2}}\right)^{0.083}
$$

$\frac{f_{s}}{f}=5.888 y^{-0.094}$

Then, the modified models of the critical gas velocity for the vortex tool can be obtained by combining the Eq. (28) or Eq. (29) with the Eq. (20) and Eq. (21), respectively. Figure 7 compares the critical gas velocities predicted by the modified models with the measured data. It can be seen that the absolute mean error of the modified model II fell below $6.6 \%$, indicating that the results of this model agree well with the measured data.

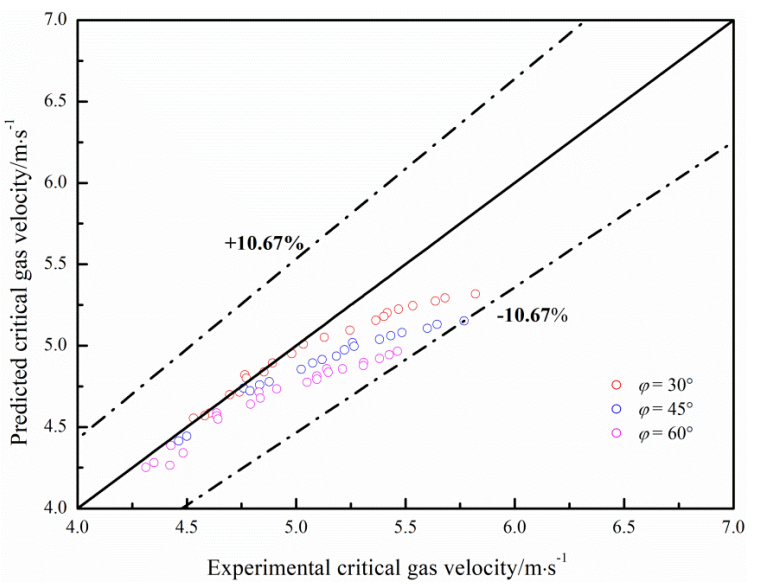

(a)

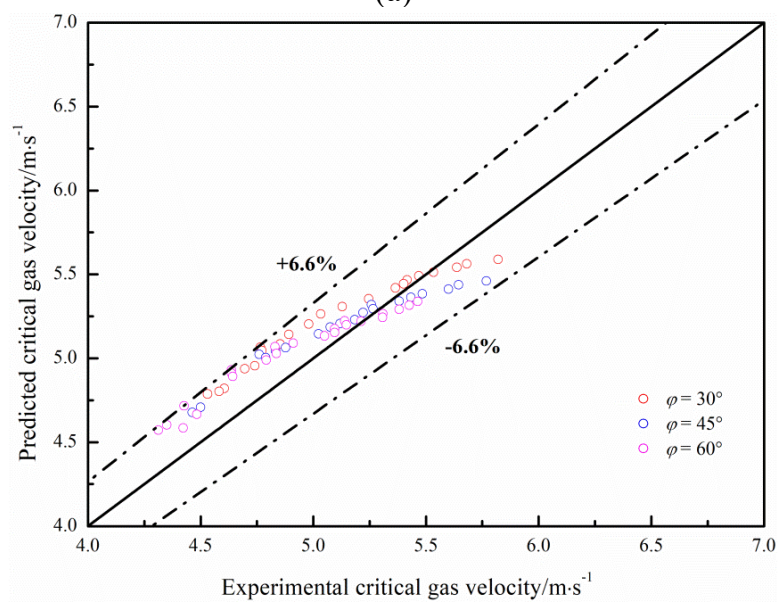

(b)

Figure 7. Comparison of critical gas velocities predicted by the modified models with the measured data: (a) Modified model I; (b) Modified model II

\subsection{Comparison of critical gas velocity prediction models with and without vortex tools}

Ali et al. [2] and Chen et al. [15] found that the vortex tool could reduce the critical gas velocity of gas wells, and the reduction amplitude was not less than $20 \%$ in their experiments. However, there is little theoretical evidence to back up their finding. Hence, the new models were contrasted against the commonly used models like the Turner model, which is a popular tool to predict the critical gas velocity of conventional gas wells without vortex tools. The Turner model can be expressed as: 
$v_{c r_{-} T}=6.6\left[\frac{\sigma\left(\rho_{l}-\rho_{g}\right)}{\rho_{g}^{2}}\right]^{0.25}$

According to Eq. (21) and Eq. (30), the relationship between the critical gas velocity prediction models with and without vortex tools can be described as:

$v_{\text {crs }}=\frac{K u}{3.73} v_{\text {cr_- } T}$

Thus, the reduction amplitude of critical gas velocity with vortex tool can be described as:

$R_{-} a m p=\frac{v_{c r_{-} T}-v_{c r s}}{v_{c r_{-} T}} \times 100 \%=1-\frac{K u}{3.73}$

It can be seen that the reduction amplitude mainly depends on the Bond number and swirling flow friction factor. Then, a typical working condition was cited as an example, in which the gas density is $6.21 \mathrm{~kg} / \mathrm{m}^{3}$ at the wellhead pressure of $3 \sim 4 \mathrm{MPa}$ [21], the liquid density is $1,000 \mathrm{~kg} / \mathrm{m}^{3}$, the gas-liquid surface tension is $0.06 \mathrm{~N} / \mathrm{m}$, and the axial friction factor of the gas-liquid two-phase flow is 0.008 . Figure 8 presents the reduction amplitudes of critical gas velocity under different hub diameters and helix angles (inner diameter of tubing: 62mm).

For gas well with vortex tool, the reduction amplitude of critical gas increased with the helix angle, but decreased slightly with the growth in hub diameter. With the helix angle varying from $15^{\circ}$ to $75^{\circ}$ and the hub diameter from $34 \mathrm{~mm}$ to $50 \mathrm{~mm}$, the critical gas velocity was $55.03 \% \sim 59.35 \%$ smaller than that of the Turner model. This means the helix angle has a greater impact than the hub diameter on the reduction amplitude. Hence, priority should be given to the helix angle in the design of vortex tools.

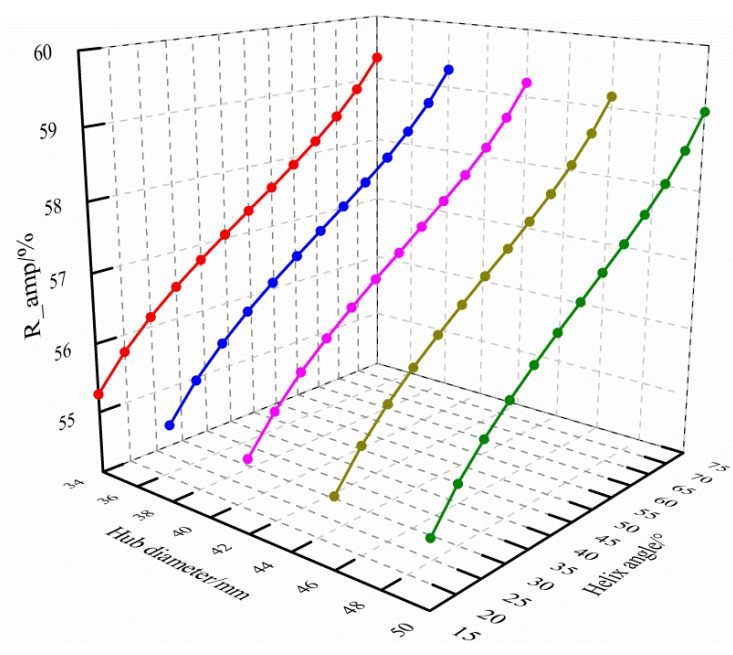

Figure 8. Reduction amplitudes of critical gas velocity under different hub diameters and helix angles

\section{FIELD TEST}

To further verify the reliability of our new model, a field test was conducted on well C45 in Xinjiang oilfield. In the later phase of well production, liquid was loaded up in the wellbore due to the low reservoir pressure. Thus, the vortex drainage gas recovery method was applied to remove the liquid. In this well, two vortex tools were installed along the tubing. The helix angle and hub diameter of the tools were $35^{\circ}$ and $42 \mathrm{~mm}$, respectively. Table 2 lists the production data of well $\mathrm{C} 45$ before and after the installation of vortex tool. The liquid loading predicted by Turner model, Li's model and the new model are compared in Table 3 . It can be seen that the results predicted by Turner model and Li's model were consistent with the actual production status before the installation of vortex tools, and the results predicted by Li's model and the new model were in agreement with the actual situation after the vortex tools installed. More field data are needed to verify the new models in future.

Table 2. Production data of well C45 before and after the vortex tool installation

\begin{tabular}{cccccccc}
\hline Measure & $\begin{array}{c}\text { Wellhead } \\
\text { pressure/ } \\
\mathrm{MPa}\end{array}$ & $\begin{array}{c}\text { Water } \\
\text { production/ } \\
\left(\mathrm{m}^{3} \cdot \mathrm{d}^{-1}\right)\end{array}$ & $\begin{array}{c}\text { Gas } \\
\text { production/ } \\
\left(10^{4} \mathrm{~m}^{3} \cdot \mathrm{d}^{-1}\right)\end{array}$ & $\begin{array}{c}\text { gas specific } \\
\text { gravity }\end{array}$ & $\begin{array}{c}\text { water specific } \\
\text { gravity }\end{array}$ & $\begin{array}{c}\text { tubing } \\
\text { diameter/ } \\
\text { mm }\end{array}$ & $\begin{array}{c}\text { Production } \\
\text { status }\end{array}$ \\
\hline Before & 4.03 & 0.52 & 1.24 & 0.583 & 1.05 & 62 & Loaded up \\
After & 4.84 & 2.05 & 1.95 & \multirow{2}{*}{$0.5 n$ loaded } \\
\hline
\end{tabular}

Table 3. The prediction results of different models on critical gas flow rate and liquid loading

\begin{tabular}{ccccc}
\hline & \multicolumn{2}{c}{ Before tool installation } & \multicolumn{2}{c}{ After tool installation } \\
\cline { 2 - 5 } Model & $\begin{array}{c}\text { Predicted critical flow } \\
\text { rate } /\left(10^{4} \mathrm{~m}^{3} \cdot \mathrm{d}^{-1}\right)\end{array}$ & $\begin{array}{c}\text { Liquid loading } \\
\text { prediction }\end{array}$ & $\begin{array}{c}\text { Predicted critical flow rate } \\
/\left(10^{4} \mathrm{~m}^{3} \cdot \mathrm{d}^{-1}\right)\end{array}$ & $\begin{array}{c}\text { Liquid loading } \\
\text { prediction }\end{array}$ \\
\hline Turner & 3.851 & Loaded up & 4.254 & Loaded up \\
$\mathrm{Li}$ & 1.459 & Loaded up & 1.612 & Unloaded \\
New & - & - & 1.812 & Unloaded \\
\hline
\end{tabular}

\section{CONCLUSIONS}

After decomposing the gas-liquid two-phase swirling flow into an axial annular flow and a tangential circular flow, this paper establishes a liquid film model to predict the critical gas velocity for vortex drainage gas wells based on the axial force balance of the liquid film and the gas core. The proposed model considers the effects of helix angle and hub diameter of the vortex tool. In this model, the swirling friction factor correlation was modified with experimental data. The prediction error by the modified critical gas velocity model was less than $6.6 \%$ compared to the measured data. In addition, 
the reduction amplitude of critical gas velocity with vortex tool was defined according to the Turner model. Through analysis, it is found that the reduction amplitude increased with the helix angle, but decreased with the growth in hub diameter. The helix angle has a greater impact than the hub diameter on the reduction amplitude. Hence, priority should be given to the helix angle in the design of vortex tools.

\section{ACKNOWLEDGEMENTS}

This paper is made possible thanks to the generous support from the National Natural Science Foundation of China (Grant No.: 61572084, 61772086) and the 13th Five-Year Plan National Major Projects (Grant No.: 2016ZX05056004002, 2016ZX05046004-003), as well as the valuable advices from editors and reviewers.

\section{REFERENCES}

[1] Simpson DA. (2003). Vortex flow technology finding new applications. The Rocky Mountain Oil Journal 83(45): $40-45$. http://www.vortextools.com/VtxTechnicalReports/Davi d_Simpson_Vortex-RMOJ_11-03.pdf

[2] Ali A, Scott S, Fehn B. (2005). Investigation of new tool to unload liquids from stripper-gas wells. SPE Production \& Facilities 20(04): 306-316. http://doi.org/10.2523/84136-ms

[3] Yang T, Yu SM, Yang H. (2012). A new technology of vortex dewatering gas recovery in gas wells and its application. Natural Gas Industry 32(8): 63-66. http://doi.org/10.3787/j.issn.1000-0976.2012.08.013

[4] Zhu Q, Zhang JJ, Xie F. (2013). Application of eddy drainage gas recovery to gas fields in Sichuan Basin. Natural Gas Technology and Economy 7(1): 37-39.

[5] Wu XD, Zhou C, An YS. (2016). Dynamic analysis of liquid droplet and optimization of helical angle for vortex drainage gas recovery. Natural Gas Industry 36(5): $45-$ 50. http://doi.org/ 10.1016/j.ngib.2016.12.010

[6] Turner RG, Hubbard MG, Dukler AE. (1969). Analysis and prediction of minimum flow rate for the continuous removal of liquids from gas wells. Journal of Petroleum Technology 21(11):

1475-1482. https://doi.org/10.2118/2198-PA

[7] Li M, Li SL, Sun LT. (2002). New view on continuousremoval liquids from gas wells. Spe Production \& Facilities 17(1): 42-46. https://doi.org/10.2118/70016MS

[8] Wang YZ, Liu QW. (2008). A new method to calculate the minimum critical liquids carrying flow rate for gas wells. Petroleum Geology and Oilfield Development in Daqing 26(6): 82-85.
[9] Belfroid S, Schiferli W, Alberts G. (2008). Predicting onset and dynamic behavior of liquid loading gas wells. Society of Petroleum Engineers 21-24. http://doi.org/10.2118/115567-MS

[10] Wang Z, Bai H, Zhu S. (2015). An entrained-droplet model for prediction of minimum flow rate for the continuous removal of liquids from gas wells. SPE Journal 20(5): 1,135-1,144. https://doi.org/10.2118/174077-PA

[11] Pan J, Wang WJ, Wei YQ. (2018). A calculation model of critical liquid-carrying velocity of gas wells considering the influence of droplet shapes. Natural Gas Industry $38(1)$ : 67-73. http://doi.org/10.1016/j.ngib.2018.01.007

[12] Richter HJ. (1981). Flooding in tubes and annuli. International Journal of Multiphase Flow 7(6): 647-658. http://doi.org/10.1016/0301-9322(81)90036-7

[13] Chen D, Yao Y, Fu G. (2016). A new model for predicting liquid loading in deviated gas wells. Journal of Natural Gas Science and Engineering 34: 178-184. http://doi.org/10.1016/j.jngse.2016.06.063

[14] Liu Y, Luo C, Zhang L. (2018). Experimental and modeling studies on the prediction of liquid loading onset in gas wells. Journal of Natural Gas Science and Engineering 57: 349-358.

[15] Chen DC, Han H, Yao Y. (2015). An experimental study on the effect of the vortex tool and its influence on critical velocity. Natural Gas Geoscience 26(11): 2137-2141. http://doi.org/10.11764/j.issn.1672-1926.2015.11.2137

[16] Zhou C, Wu XD, Tang JF. (2016). Calculation of the critical liquid carrying-over in the wellbore for downhole vortex dewatering gas recovery. Petroleum Geology and Oilfield Development in Daqing 35(6): 99-103.

[17] Wallis GB. (1969). One-dimensional two-phase flow. New York: McGraw-Hill 11(3): 445-458. http://doi.org/10.1016/0017-9310(68)90089-6

[18] Gambill WR, Bundy RD, Wansbrough RW. (1960). Heat transfer, burnout, and pressure drop for water in swirl flow through tubes with internal twisted tapes. Oak Ridge, TN: Oak Ridge National Laboratory. https://www.osti.gov/biblio/4145353

[19] Lopina RF, Bergles AE. Heat transfer and pressure drop in tape-generated swirl flow of single-phase water. Journal of Heat Transfer 91(3): 434-441. http://doi.org/10.1115/1.3580212

[20] Chen DC, Yao Y, Han H. (2016). Optimizing experiment on the liquid discharge effects and its structural parameters for gas-well vortex tool. Petroleum Geology and Oilfield Development in Daqing 35(4): 109-112. http://doi.org/10.6056/dkyqt201604028

[21] Yang XD, Li L, Zhang J. (2015). Mechanism study of downhole vortex tool for water drainage during gas production. China Petroleum Machinery 43(5): 81-86. 